mer, ${ }^{22}$ proton-transfer tautomers, ${ }^{23}$ ring-chain tautomers, ${ }^{24}$ and diastereoisomeric hemiacetals, ${ }^{25}$ as well as the isomers related by 1,3-acyl migration discussed above. In many of the cases cited it is not clear whether the selectivity observed is due to preferential nucleation of one isomer or to a thermodynamic preference for one isomer in the crystalline state.

(22) I. R. Gault, W. D. Ollis, and I. O. Sutherland, Chem. Commun., 269 (1970); N. A. Bailey and S. E. Hull, ibid., $960(1971)$; D. Y. Curtin and J. W. Hausser, J. Amer. Chem. Soc., 83, 3474 (1961); E. F. Schoenwaldt, R. B. Kinnel, and P. Davis, J. Org. Chem., 33, 4270 (1968); M. Raban and E. Carlson, J. Amer. Chem. Soc., 93, 685 (1971); A. G. Sanchez, A. M. Valle, and J. Bellanato, J. Chem. Soc. B, 2330 (1971); F. Sondheimer, Accounts Chem. Res., 3, 81 (1972); A. Rieker and H. Kessler, Chem. Ber., 102, 2147 (1969); A. J. Bellamy and R. D. Guthrie, J. Chem. Soc. C, 2090 (1968).

(23) B. H. Chase and J. Walker, J. Chem. Soc., 3518 (1953); J. W. Schulenberg, J. Amer. Chem. Soc., 90, 1367 (1968); E. M. Peresleni, M. Y. Uritskaya, V. A. Loginova, Y. N. Sheinker, and L. I. Yakontov, Dokl. Akad. Nauk SSSR, 183, 1102 (1968); G. A. Newman and P. J. S. Pauwels, Tetrahedron, 25, 4605 (1969); E. Spinner and G. B. Yeh, J. Chem. Soc. B, 279 (1971); T. Shono, Y. Hayashi, and K. Shima, Bull. Chem. Soc. Jap., 4, 3179 (1971); D. Hadzi, J. Chem. Soc., 2143 (1956); G. T'oth, I. T'oth, and L. Toldy, Tetrahedron Lett., 5299 (1969); W. Walter and K. J. Reubke, Chem. Ber., 102, 2117 (1969).

(24) P. R. Jones and P. J. Desio, J. Org. Chem., 30, 4203 (1965); W. Flitsch, Chem. Ber., 103, 3205 (1970); A. F. MeDonagh and H. E. Smith, J. Org. Chem., 33, 1 (1968); W. Schaefer and H. Schlude, Tetrahedron Lett., 2161 (1968); H. Alper, E. C. Keung, and R. A. Partis, J. Org. Chem., 86, 1352 (1971), and earlier papers.

(25) M. C. Tanret, Bull. Soc. Chim. Fr., 38, 337 (1905); C. S. Hudson and E. Yanovsky, J. Amer. Chem. Soc., 39, 1013 (1917); R. W. King, C. F. Murphey, and W. C. Wildman, ibid., 87, 4912 (1965); J. Karle, J. A. Estlin, and I. L. Karle, ibid., 89, 6510 (1967).
Differential thermal analysis in which $2 a$ was heated at a rate of $10^{\circ} / \mathrm{min}$ showed an endotherm (partial melting) interrupted by an exotherm (heat of reaction and recrystallization of the $3 a$ which had been formed) and then a melting endotherm corresponding to the melting of the product 3a. ${ }^{26}$ From the areas of these peaks the thermal changes were estimated to be 4.7 $\mathrm{kcal} / \mathrm{mol}$ for the first endotherm and $-6.9 \mathrm{kcal} / \mathrm{mol}$ for the exotherm. At the end of those changes, if melting, reaction, and recrystallization had taken place, the net change for the process $2 \mathrm{a}$ (solid) $\rightarrow 3 \mathrm{a}$ (solid) was $4.7+(-) 6.9=2.2 \mathrm{kcal} / \mathrm{mol}$. These data are not of high accuracy but the result is reasonable. The final melting endotherm had an area which gave a value for the heat of fusion of $12 \mathrm{kcal} / \mathrm{mol}$ for the $3 a$ which had been formed. The value of the heat of fusion obtained with recrystallized $3 a$ was $9.3 \mathrm{kcal} / \mathrm{mol}$. The reason for the greater stabilization of $3 a$ by crystal packing forces must await information about the crystal structures of these compounds.

Registry No. - 1, 20178-62-5; 2a, 20178-63-6; 2b, $35454-86-5 ; \quad 2 c, 35356-68-4 ; \quad 3 a, 20178-64-7$; 3b, 35427-28-2; 3c, 35356-69-5.

(26) We are indebted to Dr. S. R. Byrn for these results. The method employed has been described: D. Y. Curtin, S. R. Byrn, and D. B. Pendergrass, Jr., J. Org. Chem., 84, 3345 (1969).

\title{
Carbon-13 Nuclear Magnetic Resonance Spectroscopy. Conformational Analysis of Methyl-Substituted Cycloheptanes, Cycloheptanols, and Cycloheptanones ${ }^{1}$
}

\author{
Manfred Christla ${ }^{2}$ and John D. Roberts* \\ Contribution No. 4417 from the Gates and Crellin Laboratories of Chemistry; \\ California Institute of Technology, Pasadena, California 91109
}

Received February 8, 1978

\begin{abstract}
The ${ }^{13} \mathrm{C}$ chemical shifts were determined of the carbons in 12 cycloheptanes, 21 cycloheptanols, and 8 cycloheptanones. In some cycloheptanols and cycloheptanones, the assignments have been obtained unambiguously by the synthesis of deuterated derivatives and the use of paramagnetic-shift reagents. Substituent effects for the different types of groups have been calculated. The most informative data about the cycloheptane conformations were provided by the relatively well understood $\gamma$ effects. The results are generally in good agreement with predictions based on the twist-chair form, which has been predicted by Hendrickson to be the most stable conformation. Pairs of cis-trans isomers are found to have rather characteristic differences in their ${ }^{13} \mathrm{C}$ spectra. This fact was used to assign the resonances found for cis-trans mixtures of methyl-substituted cycloheptanols to specific isomers.
\end{abstract}

In contrast to the many published studies of cyclohexane conformations, the results of relatively few experimental investigations of the cycloheptane conformations have been reported. ${ }^{3}$ One reason is complexity. The twist-chair conformation (1) of cyclo-

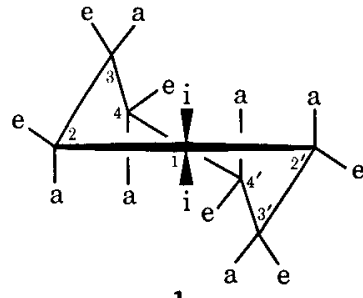

1

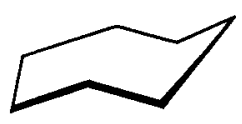

2
(1) Supported by the National Science Foundation.

(2) Max Kade Foundation, Inc., Fellow, 1970-1971.

(3) For a review see W. Tochtermann, Fortschr. Chem. Forsch., 15, 378 (1970). heptane is predicted to be most stable, ${ }^{4}$ and this form has three different equatorial (e) and axial (a) positions besides two identical isoclinal (i) or axis positions. Substituents at the $\mathrm{i}$ and the various $e$ positions are calculated to have pretty much the same conformational energy. ${ }^{4 d}$ To add to the complexities, and, in contrast to the rather rigid cyclohexane chair form, the cycloheptane twist form is quite flexible and an unsubstituted twist form can transform to another one by "pseudorotation" in which the axis of symmetry has moved by one carbon. The barrier to pseudorotation is estimated to be $1.4 \mathrm{kcal} / \mathrm{mol}^{\text {4e }}$ and the highest point of energy along the interconversion pathway is the chair form 2, which has a plane of symmetry. ${ }^{4 e}$ The twistboat (3) and the boat (4) are other cycloheptane con- 


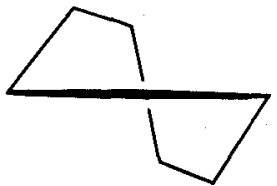

3

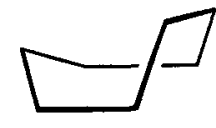

4 formations which are also relatively stable. They can also be intercoverted by pseudorotation, as for the chair forms. However, the calculated energies of 3 and 4 are higher by 2.4 and $2.7 \mathrm{kcal} / \mathrm{mol}$ than the twistchair form. ${ }^{4 c}$ It is expected, therefore, for simple substituted cycloheptanes that the boat family of forms should not be populated to more than $1 \%$ at room temperature. The results of calculations by Bixon and Lifson ${ }^{5}$ are similar to those of Hendrickson, ${ }^{4}$ except that they obtained an energy difference between twist-chair and chair conformations of only $0.7 \mathrm{kcal} / \mathrm{mol}$. The substantial flexibility of the cycloheptane ring has been demonstrated by the fluorine-labeling technique. ${ }^{6}$ The low-temperature ${ }^{19} \mathrm{~F}$ spectra were found to be different from spectra taken at room temperature only if substituents like gem-methyl groups ${ }^{6 \mathrm{a}}$ or vicinal bromine atoms $^{6 b}$ were present. Pseudorotation is clearly very rapid unless relatively large substituents are present. No evidence was found which was not in agreement with the twist-chair conformation being favored at equilibrium. Heteroatoms, such as sulfur, in a saturated seven-membered ring also seem to increase the barrier to pseudorotation. ${ }^{7} \mathrm{X}$-Ray studies of 4-bromo-6,10-dimethylbicyclo[5.3.0]decan-3-one ${ }^{8}$ and the "dimeric cycloheptanone peroxide" show that the carbocyclic seven-membered rings in these compounds prefer the chair conformation in the solid state.

Carbon-13 nuclear magnetic resonance $\left({ }^{13} \mathrm{C} \mathrm{nmr}\right)$ has been used quite successfully in conformational studies with cyclohexane, ${ }^{10-12,13 \mathrm{a}}$ cyclopentane, ${ }^{14}$ and cyclononane ${ }^{13 b}$ derivatives. Encouraged by these results, we have undertaken a ${ }^{13} \mathrm{C} \mathrm{nmr}$ investigation of cycloheptane derivatives, the results of which we report here.

\section{Results and Discussion}

The ${ }^{13} \mathrm{C}$ chemical shifts were measured at about $40^{\circ}$ and, of course, the rates of interconversion of the conformations are all exceedingly fast at this temperature. The shifts are therefore average values to which several conformations will contribute according to their popu-

(5) M. Bixon and S. Lifson, Tetrahedron, 23, 769 (1967).

(6) (a) J. D. Roberts, Chem. Brit., 529 (1966); (b) R. Knorr, C. Ganter, and J. D. Roberts, Angew. Chem., 79, 577 (1967); Angew. Chem., Int. Ed. Engl., 6, 556 (1967); (c) E. S. Glazer, R. Knorr, C. Ganter, and J. D. Roberts, J. Amer. Chem. Soc., 94, 6026 (1972).

(7) K. v. Bredow, H. Friebolin, and S. Kabuss, "Organic Chemistry, A Series of Monographs," Vol. 21, A. T. Blomquist, Ed., Academic Press, New York, N. Y., 1971, p 51.

(8) T. Sato, H. Minato, M. Shiro, and H. Koyama, Chem. Commun., 363 (1966).

(9) P. Groth, Acta Chem. Scand., 21, 2631 (1967).

(10) (a) D. K. Dalling and D. M. Grant, J. Amer, Chem. Soc., 89, 6612 (1967); (b) D. K. Dalling, D. M. Grant, and L. F. Johnson, ibid., 98, 3678 (1971); (c) H. J. Schneider, R. Price, and T. Keller, Angew. Chem., 83, 759 (1971); Angew. Chem., Int. Ed. Engl., 10, 730 (1971).

(11) (a) J. D. Roberts, F. J. Weigert, J. I. Kroschwitz, and H. J. Reich, J. Amer. Chem. Soc, 92, 1338 (1970); (b) H. J. Reich, M. Jautelat, M. T. Messe, F. J. Weigert, and J. D. Roberts, ibid., 91, 7445 (1969).

(12) G. W. Buchanan and J. B. Stothers, Can. J. Chem., 47, 3605 (1969).

(13) (a) F. A. L. Anet, C. H. Bradley, and G. W. Buchanan, J. Amer. Chem. Soc., 93, 258 (1971); (b) F. A. L. Anet and J. J. Wagner, ibid., 93, 5266 (1971).

(14) M. Christl, H. J. Reich, and J. D. Roberts, ibid., 93, 3463 (1971). lations as determined by the Boltzmann distribution. To assign the resonance lines to specific carbons, we used off-resonance proton decoupling and, whenever possible, specific proton decoupling.

A. Methylcycloheptanes. - The chemical shifts of methylcycloheptanes, kindly supplied by Professor James B. Hendrickson, ${ }^{15}$ have been determined in carbon disulfide as solvent, with tetramethylsilane as internal reference. Some representative cycloheptanes were also run in dioxane as solvent, which also served as internal reference. In dioxane, the shifts were uniformly upfield by about $1 \mathrm{ppm}$, compared to carbon disulfide. The results are summarized in Table I, while Table II gives the substituent effects of the methyl groups which result by comparison of the chemical shifts of a particular methyl-substituted cycloheptane with a corresponding cycloheptane having one less methyl group. The substituent effects are classified as $\alpha, \beta, \gamma, \delta$, and $\epsilon$ effects $^{11 \alpha}$ and listed along with the previously determined methyl substituent effects for eyclohexanes. ${ }^{10 a}$ The $\alpha$ effect is that produced by a methyl on a carbon to which it is directly attached, the $\beta$ effect is on the carbon next removed, and so on.11a Considerable difficulties will be encountered later in discussion of the shift changes by a need to distinguish between the numbering of positions for nomenclature purposes and the numbering of carbons in the twistchair conformation where the isoclinal carbon will be taken as C-1. In order to clarify this, we will use C-1i, $\mathrm{C}-2 \mathrm{e}, \mathrm{a}$, etc., when we refer to the carbons of conformations, and omit the lower case letters otherwise.

In methylcycloheptane, the resonances of three methylene carbons can be readily distinguished. Compared to the unsubstituted cycloheptane, the resonance of C-2 at $155.0 \mathrm{ppm}$ is shifted downfield by $9.3 \mathrm{ppm}$ by the $\beta$ effect of the methyl group. The position corresponding to C-3 is the result of a 1.3-ppm upfield $\gamma$ effect, while the line for C-4 is $0.7 \mathrm{ppm}$ downfield. The $\alpha$ and $\beta$ effects have about the same magnitude as for methylcyclohexane. ${ }^{10 \mathrm{a}}$ The $\gamma$ effect, however, is increased by $0.8 \mathrm{ppm}$. Because the $\gamma$ effect appears to arise from direct steric interactions between the groups under consideration, it is believed to be relatively well understood. ${ }^{14}$ We assume here that the larger $\gamma$ effect arises from a stronger average interaction between the methyl group and C-3 in methylcycloheptane than in methylcyclohexane. In this connection and in others to be discussed later, it is helpful to have Hendrickson's values for the steric interaction energies of a single methyl group with the other atoms of cycloheptane. ${ }^{4 d}$

$\begin{array}{cc}\text { Position } & \text { Calcd energy, kcal/mol } \\ 1 \mathrm{i} & 0.5 \\ 2 \mathrm{e}, 2 \mathrm{e}^{\prime} & 0.4 \\ 2 \mathrm{a}, 2 \mathrm{a}^{\prime} & 3.0 \\ 3 \mathrm{e}, 3 \mathrm{e}^{\prime} & 0.3 \\ 3 \mathrm{a}, 3 \mathrm{a}^{\prime} & 3.3 \\ 4 \mathrm{e}, 4 \mathrm{e}^{\prime} & 0.4 \\ 4 \mathrm{a}, 4 \mathrm{a}^{\prime} & 1.8\end{array}$

The most stable conformation of 1,1-dimethylcycloheptane should be $\mathbf{5}$, which is a twist-chair form with both methyl groups in the favorable isoclinal positions.

(15) J. B. Hendrickson and R. K. Boeckman, Jr., J. Org. Chem., 36, 2315 (1971). 
TABLE I

${ }^{13}$ C Chemical Shifts (in PpM) of Methylcycloheptanes Relative to Carbon Disulfide

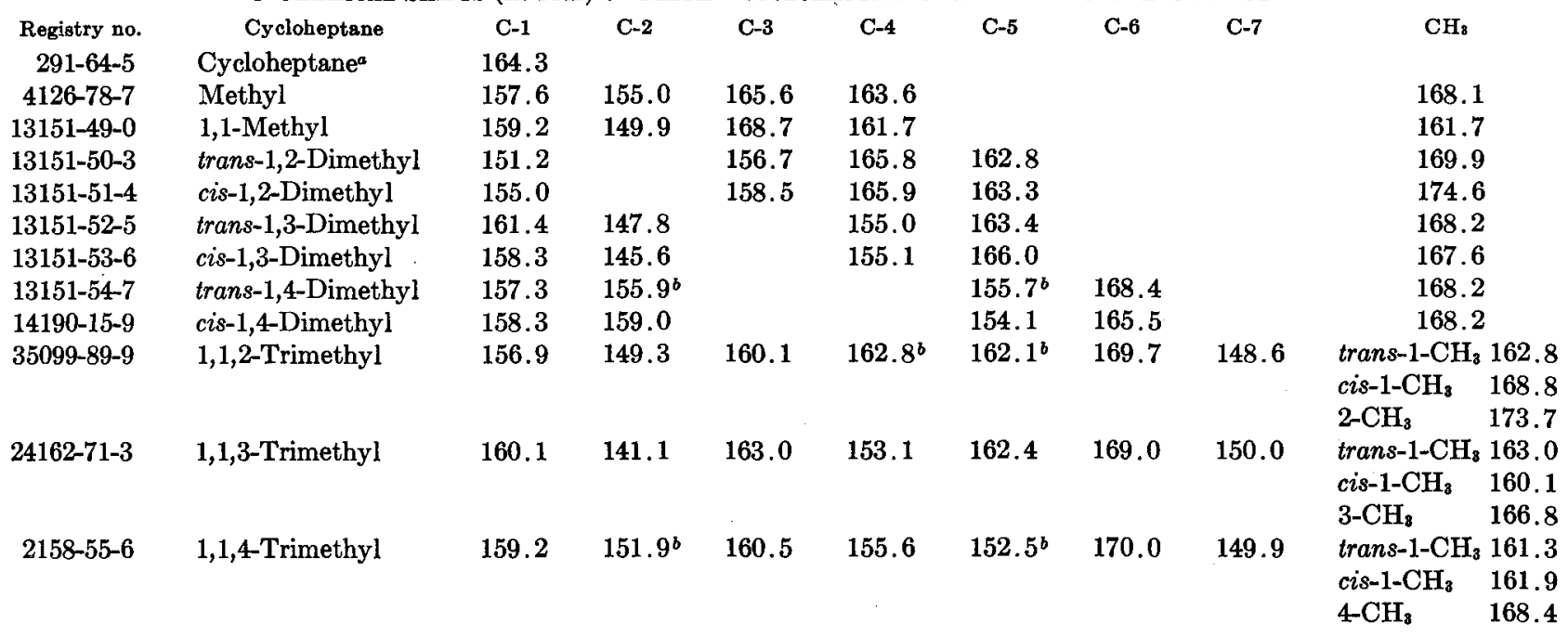

a J. J. Burke and P. C. Lauterbur, J. Amer. Chem. Soc., 86, 1870 (1964). $\quad{ }^{b}$ Tentative assignments.

Table II

${ }^{13}$ C Chemical-Shift Substituent Effects (in ppm) Produced by Substitution of a Methyl Group on Cycloheptane (CycloheXane), Methylcycloheptane (MethylcycloheXane), and 1,1-Dimethylcycloheptane (1,1-DimethylcycloheXane)a

$\begin{array}{lcc}\text { Cycloheptane (cyclohexane) } & \alpha \text { Effect } & \beta \text { Effect } \\ \text { Methyl } & -6.7 & -9.3 \\ & (-6.0) & (-8.7) \\ \text { 1,1-Dimethyl } & 1.6 & -5.1,-6.4^{b} \\ \text { trans-1,2-Dimethyl } & (3.1) & \left(-4.1,-6.1^{b}\right) \\ \text { cis-1,2-Dimethyl } & (-3.8 & -6.4,-8.9 \\ & 0.0 & (-6.5,-9.6) \\ \text { trans-1,3-Dimethyl } & -4.3) & -2.6,-7.1 \\ & (-0.5) & (-1.4,-5.0) \\ \text { cis-1,3-Dimethyl } & -7.3 & -9.4,-8.5 \\ & (-6.3) & (-8.9,-9.0) \\ \text { trans-1,4-Dimethyl } & -6.3 & -9.7, \text { or }-9.9 \\ & & -7.9 \text { or }-7.7 \\ & (-6.2) & (-9.1) \\ \text { cis-1,4-Dimethyl } & -5.3 & -6.6,-9.5 \\ & (-3.7) & (-4.4) \\ \text { 1,1,2-Trimethylc } & -0.6 & -2.3,-8.6 \\ & (-2.0) & (-2.9,-8.7) \\ \text { 1,1,3-Trimethylc } & -5.7 & -8.8,-8.6 \\ & (-5.7) & (-9.5,-9.0) \\ \text { 1,1,4-Trimethylc } & -6.1 & -8.2,-9.2 \\ & & \text { or }-9.8\end{array}$

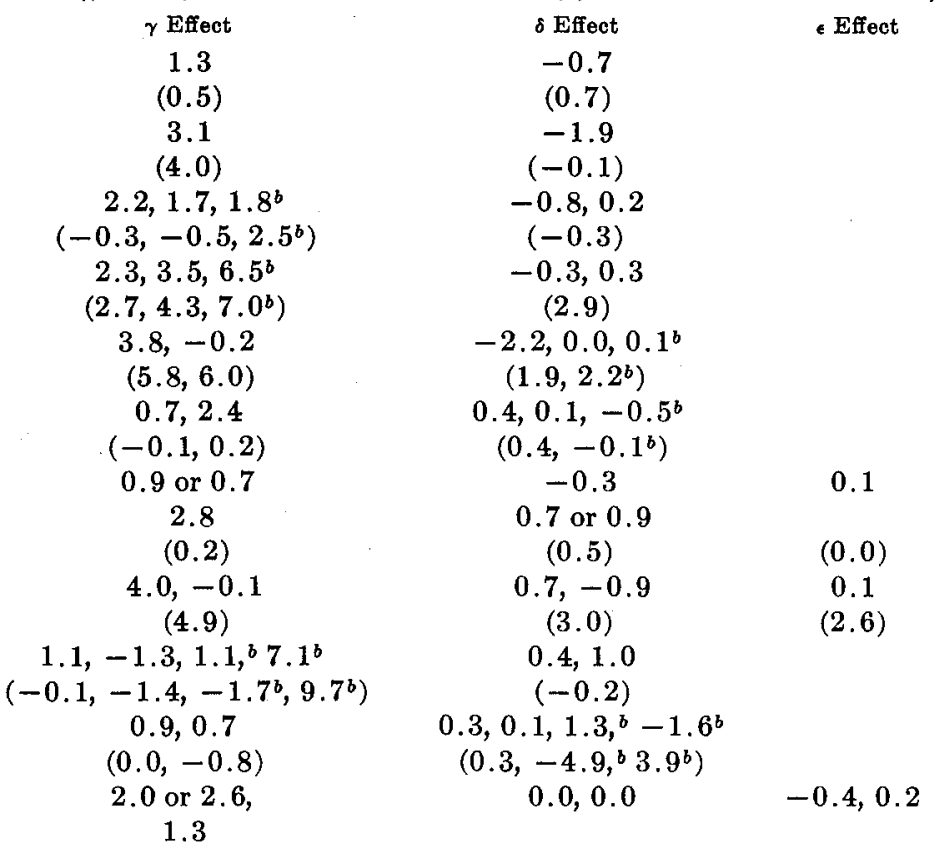

${ }^{a}$ Parenthetical values are for cyclohexane derivatives. ${ }^{b}$ Effect on the ${ }^{13} \mathrm{C} \mathrm{nmr}$ shift of a methyl already present. ${ }^{c}$ Substituent effects relative to 1,1-dimethylcycloheptane.

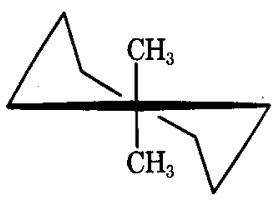

5

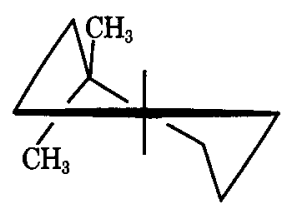

6
The $\gamma$ effect of the second methyl group is $3.1 \mathrm{ppm}$, which is $0.9 \mathrm{ppm}$ less than in 1,1-dimethylcyclohexane, which indicates less axial character. The same trend is found in the $\alpha$ and $\beta$ effects, which are less positive and more negative, respectively, than for 1,1-dimethylcyclohexane. However, $3.1 \mathrm{ppm}$ for the $\gamma$ effect is more than twice as much as in methylcycloheptane. Conformation 6 , with the methyl groups in the $4 \mathrm{e}$ and $4 \mathrm{a}$ positions, should be only about $1.2 \mathrm{kcal} / \mathrm{mol}$ less stable than 5, and may well be sufficiently populated to impose some average axial character to the methyl groups. The substituent effects seem to provide unambiguous assignments of the ${ }^{13} \mathrm{C} \mathrm{nmr}$ resonances of the cis- and trans-1,2-dimethylcycloheptanes. The serious steric interaction between the methyl groups in the cis isomer produces a large upfield shift of the methyl carbons, as has been observed in other similar compounds. ${ }^{10 a, 11 a, 14}$ The substituent effects in these isomers show the same regularities as in the 1,2-dimethylcyclohexanes. The $\alpha$ and $\beta$ effects are more negative in the trans isomer, while the $\gamma$ effects are larger in the cis isomer. In the most stable conformation of the latter, the methyl groups should occupy the 
$\mathrm{i}$ and $2 \mathrm{e}$ or $2 \mathrm{e}^{\prime}$ positions of the twist-chair (7). All the other conformations should be more than $1 \mathrm{kcal} / \mathrm{mol}$

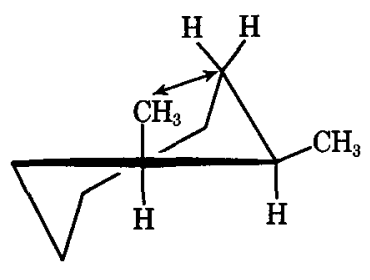

7

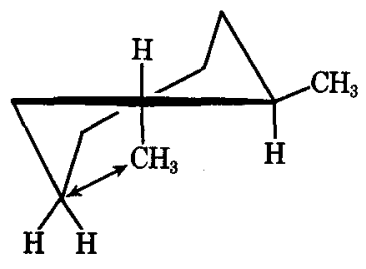

8 less stable but, because of their large number, they could well be considerably populated and, on the basis of Hendrickson's calculations, ${ }^{4 \mathrm{~d}}$ the axial character of the methyl groups can be estimated to be $10 \%$. For the trans isomer 8, a much larger number of favorable conformations is possible and the axial character of the methyl groups should be below $1 \%$. As a consequence of the relatively small difference in the conformational character of the methyl groups, their substituent effects do not differ so much between the cis and trans cycloheptane isomer as for the corresponding cyclohexanes, where the difference in the axial character is $50 \%$. The two $\gamma$-methyl effects on the ring carbons in the cis isomer are different, being 2.3 and $3.5 \mathrm{ppm}$. This can be explained by an important contribution of 7 , in which introduction of an isoclinal methyl group will give a greater interference with the ring carbon adjacent to the methyl already present, rather than the one on the unsubstituted side. With the trans isomer, the situation is just reversed for the analogous conformation, as can be seen from 8 . However, both the size of the effects and their difference is smaller for the trans isomer because 8 is not the most favorable form. Other favorable conformations with the methyl groups in the $2 \mathrm{e}, 3 \mathrm{e}, 3 \mathrm{e}, 4 \mathrm{e}, 4 \mathrm{e}, 4 \mathrm{e}^{\prime}, 4 \mathrm{e}^{\prime}, 3 \mathrm{e}^{\prime}$, and $3 \mathrm{e}^{\prime}, 2 \mathrm{e}^{\prime}$ positions should have smaller $\gamma$ interactions, about the same magnitude as for methylcycloheptane itself. This is borne out by thermochemical data which show the enthalpy difference between the cis- and trans-1,2-dimethylcycloheptanes to be $0.7 \mathrm{kcal} / \mathrm{mol}^{16}$ compared to $1.87 \mathrm{kcal} /$ $\mathrm{mol}^{17}$ between the corresponding cyclohexanes. The enthalpy differences between the cis- and trans-1,3- and -1,4-dimethylcycloheptanes are close to zero, ${ }^{16}$ while 1.96 and $1.90 \mathrm{kcal} / \mathrm{mol}$ have been determined for the corresponding cyclohexanes. ${ }^{17}$ These results follow from the average degree of axial character of the methyl groups which, from Hendrickson's ${ }^{4 d}$ conformational energies of methyl groups, are indicated to be only about $6 \%$ for the 1,3-dimethylcycloheptanes and $2 \%$ for the 1,4-dimethylcycloheptanes. Nonetheless, the ${ }^{13} \mathrm{C} \mathrm{nmr}$ spectra seem sensitive to even the small differences for the 1,3 and 1,4 isomers. For the 1,2-dimethylcycloheptanes, the substituent effects resulting from introduction of the second methyl group are substantially different for the cis and trans isomers. With the 1,3-dimethylcycloheptanes, these differences decrease and become still smaller for the 1,4-dimethyl compounds.

(16) G. Mann, M. Mühlstädt, R. Miiller, E. Kern, and W. Hadeball, Tetrahedron, 24, 6941 (1968).

(17) E. L. Eliel, N. L. Allinger, S. J. Angyal, and G. A. Morrison, "Conformational Analysis," Interscience, New York, N. Y., 1965, p 53.
The $\gamma$ effects are especially interesting. The trans1,3-dimethylcycloheptane should only be favorably disposed as 9 and 10, because in these conformations

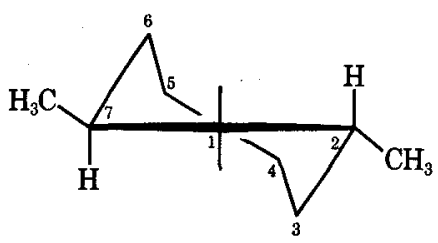

9

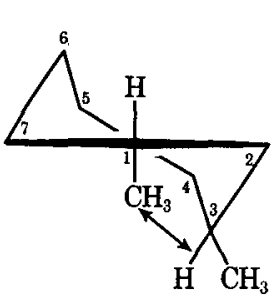

10

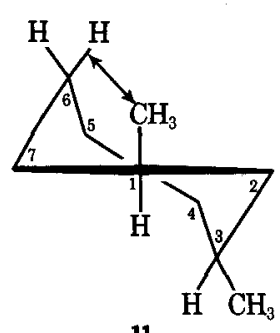

11 both methyl groups are placed in positions of minimum strain. The other trans conformations have at least one axial-type interaction. It is evident from 10 that an isoclinal methyl group should interact more strongly with $\mathrm{C}-3$ than with $\mathrm{C}-6$, which is reflected in the corresponding 3.8- and $-0.5-\mathrm{ppm} \gamma$ effects. The interaction with $\mathrm{C}-6$ is the stronger one (2.4 ppm) in cis-1,3dimethylcycloheptane, while the C-3 resonance is shifted upfield only by $0.7 \mathrm{ppm}$, both of which can be accounted for by 11 . The effects are smaller than in the trans compound, because for the cis compound there are two other conformations, $2 \mathrm{e}, 4 \mathrm{e}$ and $3 \mathrm{e}, 5 \mathrm{e}$, which are quite favorable. This analysis is borne out by the shifts of the methyl carbons of the trans isomer, which appear at $0.6 \mathrm{ppm}$ higher field than those of the cis isomer, in accord with greater average steric interactions of trans methyl groups. The methyl carbons of the cis- and trans-1,4-dimethylcycloheptanes have the same chemical shift. This is not surprising on the basis of the predicted difference in the interactions of the methyl groups in both the isomers. Again, the $\gamma$ effects show a remarkable asymmetry. The C-3 interaction expected for conformation 12 of the cis isomer amounts to $4.0 \mathrm{ppm}$, which is close to the $4.9 \mathrm{ppm}$ found for cis-1,4-dimethylcyclohexane. Practically no effect is found on the shift of C-7. Conformation 12, one of

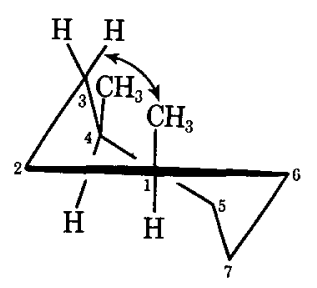

12

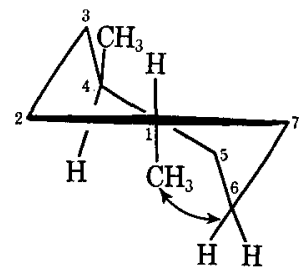

13 the favorable forms of the cis isomer, explains this well, while the interactions expected for 13 account for the reverse situation with the trans compound.

1,1,2-Trimethylcycloheptane (14) was not obtained pure. Dehydration of 1,2,2-trimethylcycloheptanol (15) yielded a mixture of cycloalkanes which, on hydrogenation, give a mixture of cycloalkanes. Gas chro- 


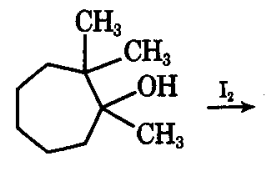

15

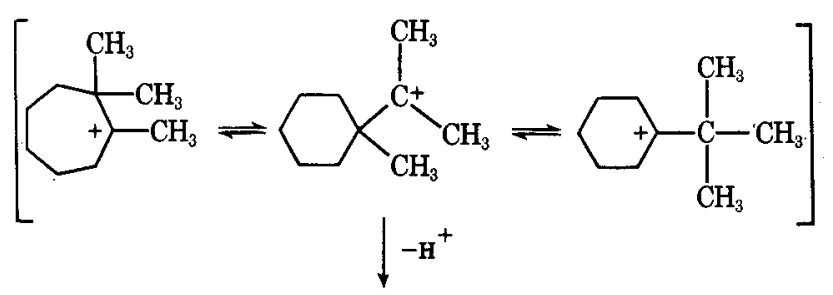

cycloalkenes

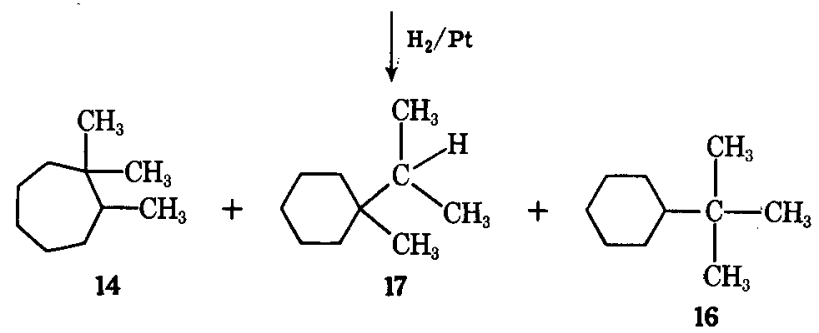

matography of this mixture with two different columns showed it to be composed largely $(88 \%)$ of two substances in equal amounts, one of which, from the ${ }^{13} \mathrm{C}$ $\mathrm{nmr}$ spectrum, was clearly tert-butylcyclohexane (16). ${ }^{11 \mathrm{a}}$ Twelve other ${ }^{13} \mathrm{C} \mathrm{nmr}$ resonances remained to be identified. Taking into account only tertiary carbonium ions in the dehydration of 15 , the reasonable other products appear to be 1-methyl-1-isopropylcyclohexane (17) or the desired 1,1,2-dimethylcycloheptane (14). One would expect 17 to exhibit seven ${ }^{18} \mathrm{C}$ nmr resonance lines, while 14 should have ten. Prediction of the line positions of 17 from related compounds ${ }^{10 a, 18}$ gives a poor fit to the observed shifts, and the intensity ratios of the peaks are also incorrect. The most appropriate fit to the ten resonances expected for 14 are shown in Table I. Each of these assignments agrees with the off-resonance proton decoupled spectra. Two further resonances at 156.1 and $170.5 \mathrm{ppm}$ were not assigned and were believed to arise from the $12 \%$ of remaining impurities. The substituent effects of the 2-methyl group (Table II) relative to 1,1-dimethylcycloheptane fit well in the general pattern of the substituent effects in methylcycloheptanes. 1,1,4-Trimethylcycloheptane was obtained by dehydration of 1,4,4-trimethylcycloheptanol and hydrogenation of the cycloalkene product. No rearrangement was detected.

It is evident from Table II that the $\gamma$ effects of the $2-, 3-$, and 4-methyl groups in 1,1,2-, 1,1,3-, and 1,1,4trimethylcycloheptanes, respectively, are relatively small. If an additional methyl group is substituted on 1,1-dimethylcycloheptane, it can go to an equatorial position (18, 19, and 20) in which, at most, only a small $\gamma$ interaction would be expected. In 1,1,2-dimethylcycloheptane, the assignment of the 1-methyl group, which is cis to the 2-methyl group, is facilitated by the direct steric interaction of these two groups, which produces a considerable differential between the shifts of the gem-methyl carbons (168.8 and $162.8 \mathrm{ppm})$. These $\gamma$ effects of the 2-methyl are 1.1 and $7.1 \mathrm{ppm}$, slightly smaller than for trans-1,2-dimethyl- $(1.8 \mathrm{ppm})$ and

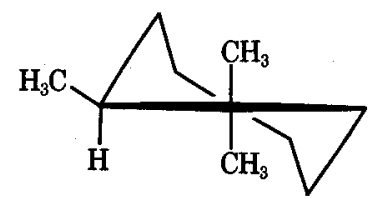

18

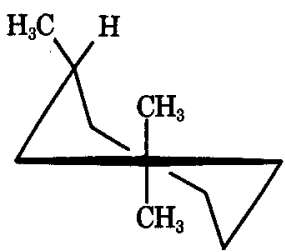

19

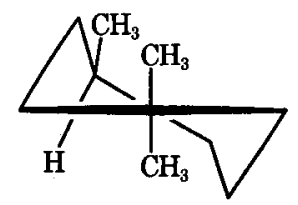

20 slightly larger than for cis-1,2-dimethylcycloheptane $(6.5 \mathrm{ppm})$.

B. Methylcycloheptanols. - There have been several studies in recent years dealing with the conformations of substituted cycloheptanols. ${ }^{19-22}$ In general, the results show the same kinds of regularities in spectra which are characteristic of the corresponding cyclohexanols, i.e., that, in the trans-2-, cis-3-, and trans-4methyl cycloheptanols, the hydroxyl group has more equatorial character than in the corresponding cis, trans, and cis isomers. However, the differences between cis-trans isomeric pairs are not usually so large as between the cyclohexanols. In the monomethylcycloheptanols, differences are greatest for the 2-methyl isomers. Borsdorf and coworkers ${ }^{21}$ have used Hendrickson's conformational energies ${ }^{4 d}$ to calculate the differences in the axial character of the hydroxyl groups between cis-trans isomers for the 2-, 3-, and 4-methylcycloheptanols to be 23,16 , and $7 \%$, respectively. With the corresponding methylcyclohexanols, the difference is expected to be about $70 \%$ for all three isomer pairs, if the conformational energy of a hydroxyl group is taken to be about one-half of that of a methyl group. For this kind of analysis, the proton spectra of dimethyl sulfoxide solutions are especially informative, ${ }^{21}$ because they give the chemical shift of the hydroxyl proton, and with secondary alcohols, the coupling constant with the carbinyl proton. These parameters have been shown to depend systematically on the axial character of the hydroxyl group. ${ }^{23,24}$ We have used this approach to characterize the secondary cycloheptanols used in this study, especially for mixtures, to determine which of the two isomers is the more abundant. It has also turned out that, for pairs of tertiary cycloheptanol isomers, the one with the more axial hydroxyl group has the more upfield hydroxyl proton chemical shift. The hydroxyl proton chemical shifts and coupling constants are collected in Table III.

All the cycloheptanols reported here were prepared be reduction of the corresponding ketones, which, in turn, were obtained by published procedures. Lithium aluminum hydride reduction of 3 - and 4-methyl- and cis-3,5-dimethylcycloheptanone produced cis-trans mixtures of alcohols in ratios too close to $1: 1$ to permit

(19) W. Hückel and J. Wächter, Justus Liebigs Ann. Chem., 672, 64 (1964). (20) W. Hückel and O. Honecker, ibid., 678, 10 (1964).

(21) A. Zschunke, F.-J. Striber, and R. Borsdorf, Tetrahedron, 24, 4403 (1968).

(22) H. Baumann, H. Moehrle, and A. Dieffenbacher, ibid., 25, 135 (1969)

(23) O. L. Chapman and R. W. King, J. Amer. Chem. Soc., 86, 1256 (1964)

(24) C. P. Rader, ibid., 91, 3248 (1969). 
TABLE III

Hydroxyl Proton Chemical Shifts (in ppm Downfield From EXTERnal TETramethylsilanE ${ }^{a}$ ) AND H-C-OH Coupling Constants (in $\mathrm{Hz}$ ) of Cycloheptanols in Dimethyl Sulfoxide Solution

\begin{tabular}{|c|c|c|c|}
\hline Registry no. & Substituent & $\delta$ & $J$ \\
\hline $502-41-0$ & None $^{b}$ & 4.26 & 4.0 \\
\hline $19790-05-7$ & trans-2-Methylc & 4.23 & 5.0 \\
\hline $19790-04-6$ & cis-2-Methylc & 4.05 & 4.4 \\
\hline $933-16-4$ & $\operatorname{trans-3-Methylc}$ & 4.13 & 3.8 \\
\hline $933-15-3$ & cis-3-Methylc & 4.17 & 4.2 \\
\hline $10126-52-0$ & trans-4-Methylc & 4.23 & 4.0 \\
\hline $19790-06-8$ & $c i s-4-M^{2}$ thylc & 4.20 & 4.0 \\
\hline $1194-32-7$ & 2,2-Dimethyl & 4.11 & 4.6 \\
\hline $35099-83-3$ & 3,3-Dimethyl & 4.12 & 4.1 \\
\hline $35099-84-4$ & 4,4-Dimethyl & 4.27 & 4.3 \\
\hline $35099-37-7$ & trans,trans-3,5-Dimethyl & 4.17 & 4.0 \\
\hline $35099-38-8$ & cis,cis-3,5-Dimethyl & 4.17 & 4.0 \\
\hline $3761-94-2$ & 1-Methyl & 3.96 & \\
\hline 35099-39-9 & trans-1,2-Dimethyl & 3.67 & \\
\hline $35099-40-2$ & cis-1,3-Dimethyl & 3.91 & \\
\hline $35099-41-3$ & trans-1,3-Dimethyl & 3.94 & \\
\hline $35099-42-4$ & trans-1,4-Dimethyl & 3.91 & \\
\hline $35099-43-5$ & cis-1,4-Dimethyl & 3.95 & \\
\hline $35099-86-6$ & 1,2,2-Trimethyl & 3.63 & \\
\hline $35099-87-7$ & 1,3,3-Trimethyl & 3.79 & \\
\hline $35099-88-8$ & 1,4,4-Trimethyl & 3.93 & \\
\hline
\end{tabular}

${ }^{a}$ The low-field ${ }^{13} \mathrm{C}$ satellite of the dimethyl sulfoxide protons at $\delta 3.68^{23}$ was used as internal reference. ${ }^{b}$ From ref $21 .^{c}$ Slightly different values are reported in ref 21 .

assignment of the resonances to specific isomers on the basis of resonance intensities. In these cases, one of the two isomers was concentrated by chromatography on neutral alumina, or else a different ratio from $1: 1$ of alcohols was obtained by catalytic hydrogenation. The tertiary cycloheptanols were synthesized from the ketones and methyllithium. In these reactions, the isomers were not formed in the same amount.

The ${ }^{13} \mathrm{C}$ chemical shifts of 21 cycloheptanols and the substituent effects of the hydroxyl groups are shown in Table IV. Based on these parameters, the assignment of most of the resonance lines to specific carbons seems to be rather unambiguous. A few critical choices have been examined in detail, as by introduction of deuterium instead of hydrogen in specific locations, which causes almost complete loss of the signal of the directly attached carbon in the noise-decoupled spectra. ${ }^{11 b}$ Thus, investigation of cis- and trans-2-methylcycloheptanol$2,7,7-d_{3}$ led to the unambiguous assignment of C-7 in these compounds. The ${ }^{13} \mathrm{C} \mathrm{nmr}$ spectra of cis- and trans-3-methylcycloheptanol- $2,2,7,7-d_{4}$ and $-2,2,6,6-$ $d_{4}$, as well as cis- and trans-4-methylcycloheptanol$2,2,7,7-d_{4}$ and $-3,3,7,7-d_{4}$, permitted conclusive assignment of all of the carbons of the 3- and 4-methylcycloheptanols. Lanthanide shifts induced by europium tris(dipivaloylmethane), $\mathrm{Eu}(\mathrm{DPM})_{3}$, and europium tris $(1,1,1,2,2,3,3$-heptafluoro-7,7-dimethyl-4,6-octanedione), $\operatorname{Eu}(\mathrm{fod})_{3}$, have been useful with our cycloheptanols. Downfield shifts of the resonances in the proton $^{25,26}$ and carbon-13 spectra ${ }^{14,27}$ were observed and, because the effects normally (but by no means invariably) decrease with increasing distance of the nu-

(25) J. K. M. Sanders and D. H. Williams, J. Amer. Chem. Soc., 98, 641 (1971), and references cited therein.

(26) R. E. Rondeau and R. E. Sievers, ibid., 98, 1524 (1971).

(27) J. Briggs, F. A. Hart, G. P. Moss, and E. W. Randall, Chem. Commun., 364 (1971). cleus under consideration from the europium atom, assignments can be made on the basis of the relative size of the pseudocontact shifts within a molecule. The measured shifts for benzene solutions of the alcohols are shown in Table V. In the absence of the lanthanide complexes, the ${ }^{13} \mathrm{C} \mathrm{nmr}$ shifts differ only a few tenths of a part per million from those in Table IV, all of which were obtained for dioxane solutions. In contrast, the shifts of the methylcycloheptanes (Table I) are for carbon disulfide solutions, in which all resonances are shifted downfield by about $1 \mathrm{ppm}$, compared to dioxane. This should be kept in mind in discussion of the hydroxyl group substituent effects, which are calculated by subtraction of the chemical shifts of the corresponding cycloheptane from those of the cycloheptanol. Thus, the solvent influence makes all hydroxyl group substituent effects more positive by about $1 \mathrm{ppm}$.

The magnitudes of the hydroxyl group $\gamma$ effects are sufficiently large for the monomethylcycloheptanols to make the uncertainties in them due to solvent effects unimportant. This should be no surprise after the discussion of the substituent effects in the dimethylcycloheptanes, where the axial character, if any, is divided between the two methyl groups. In the methylcycloheptanols, the methyl group, being the larger group, tends to occupy the equatorial positions, thus imposing axial character on the hydroxyl group which results in substantial $\gamma$ interactions. For trans-2-, cis-3-, and trans-4-methylcycloheptanol, the sum of both the $\gamma$ effects is smaller than in the corresponding cis, trans, and cis isomers, in accordance with expectations of the axial character of the hydroxyl groups in these compounds. ${ }^{21}$ However, the $\gamma$ effects in the former isomers are relatively large compared to those for corresponding cyclohexanols ${ }^{11 \mathrm{a}}$ or for cycloheptanol itself. This may indicate some degree of population of conformations with axial hydroxyl groups or an increased $\gamma$ effect of hydroxyl groups when forced into the isoclinal positions of the twist-chair (1) by having the methyl groups go equatorial.

The general pattern of the substituent effects in the cycloheptanols is very similar to that for the methylcycloheptanes. Cis-trans isomeric pairs display the same systematic differences in the $\alpha, \beta$, and $\gamma$ effects which decrease in going from the 2-methyl- to the 3methyl- and finally to the 4-methylcycloheptanols. The asymmetry of the $\gamma$ interactions discussed earlier is also observed. For cis-2-methylcycloheptanol, a large chemical-shift effect on the methyl carbon results from the direct steric interaction of the substituents, as has been observed also for cis-2-methylcyclohexanol ${ }^{11 a}$ and cyclopentanol. ${ }^{14}$

The $\gamma$ effects of the hydroxyl groups in the geminal dimethylcycloheptanols are larger than expected because of the tendency of the hydroxyl group to be forced into axial positions. The difference between the chemical shifts of the two methyl carbons in 2,2-dimethylcycloheptanol is Iarger than between those of the methyl carbons in the two 2-methylcycloheptanols and, because of the direct steric interaction with the hydroxyl group, the resonance of the cis methyl group should be the one at the higher field.

In 4,4-dimethylcycloheptanol, the asymmetry introduced by the hydroxyl group is not sufficient to make 
TABLE IV

${ }^{13} \mathrm{C}$ Chemical Shifts of Cycloheptanols ${ }^{a}$

\begin{tabular}{|c|c|c|c|c|c|c|c|c|c|c|c|}
\hline Substituents & C-1 & $\mathrm{C}-2$ & $\mathrm{C}-3$ & C-4 & $\mathrm{C}-5$ & $\mathrm{C}-6$ & $\mathrm{C}-7$ & $1-\mathrm{CH}_{8}$ & & $2-, 3-, 4-, 5-\mathrm{CH}_{3}$ & \\
\hline \multirow[t]{2}{*}{ None $^{b}$} & 120.1 & 154.8 & 169.2 & 163.9 & & & & & & & \\
\hline & -44.2 & -9.5 & 4.9 & -0.4 & & & & & & & \\
\hline \multirow[t]{2}{*}{ trans-2-Methyl } & 115.2 & 150.8 & 160.8 & 166.8 & 164.7 & 170.7 & 156.5 & & trans-2-CH & 172.3 & \\
\hline & -39.8 & -6.8 & 5.8 & 1.2 & 1.1 & 7.1 & -9.1 & & & 4.2 & \\
\hline \multirow[t]{2}{*}{ cis-2-Methyl } & 119.3 & 154.1 & 163.1 & 167.0 & 164.8 & 170.6 & 158.2 & & cis-2-CH & 175.2 & \\
\hline & -35.7 & -3.5 & 8.1 & 1.4 & 1.2 & 7.0 & -7.4 & & & 7.1 & \\
\hline \multirow[t]{2}{*}{ trans-3-Methyl } & 124.3 & 147.6 & 165.1 & 155.7 & 165.1 & 169.1 & 155.7 & & trans $-3-\mathrm{CH}_{3}$ & 169.1 & \\
\hline & -41.3 & -7.4 & 7.5 & 0.7 & -0.5 & 5.5 & -7.9 & & & 1.0 & \\
\hline \multirow[t]{2}{*}{ cis-3-Methyl } & 121.9 & 146.0 & 162.9 & 156.3 & 166.9 & 170.4 & 155.3 & & $c i s-3-\mathrm{CH}_{8}$ & 168.9 & \\
\hline & -43.7 & -9.0 & 5.3 & 1.3 & 1.3 & 6.8 & -8.3 & & & 0.8 & \\
\hline \multirow[t]{2}{*}{ trans-4-Methyl } & 121.0 & 157.1 & 161.1 & 158.6 & 156.4 & 172.3 & 155.7 & & trans-4- $\mathrm{CH}_{2}$ & 2169.3 & \\
\hline & -42.6 & -8.5 & 6.1 & 1.0 & 1.4 & 6.7 & -7.9 & & & 1.2 & \\
\hline \multirow[t]{2}{*}{ cis-4-Methyl } & 121.9 & 158.7 & 163.1 & 159.0 & 155.4 & 170.4 & 155.1 & & $c i s-4-\mathrm{CH}_{4}$ & 169.3 & \\
\hline & -41.7 & -6.9 & 8.1 & 1.4 & 0.4 & 4.8 & -8.5 & & & 1.2 & \\
\hline \multirow[t]{2}{*}{ 2,2-Dimethyl } & 113.8 & 155.6 & 153.6 & 171.0 & 164.6 & 168.6 & 159.9 & & trans $-2-\mathrm{CH}_{8}$ & 164.6, cis $-2-\mathrm{CH}_{3}$ & 170.5 \\
\hline & -36.1 & -3.6 & 3.7 & 1.3 & 2.9 & 6.9 & -8.8 & & & 2.9 & 8.8 \\
\hline \multirow[t]{2}{*}{ 3,3-Dimethyl } & 124.9 & 141.2 & 162.0 & 150.7 & 170.1 & 166.8 & 153.5 & & $\operatorname{trans}-3-\mathrm{CH}_{3}$ & ${ }_{3} 163.7$, cis $-3-\mathrm{CH}_{3}$ & 161.0 \\
\hline & -43.8 & -8.7 & 2.8 & 0.8 & 1.4 & 5.1 & -8.2 & & & 2.0 & -0.7 \\
\hline \multirow[t]{2}{*}{ 4,4-Dimethyl } & 120.6 & 161.2 & 153.4 & 160.3 & 150.8 & 174.0 & 157.6 & & trans-4- $\mathrm{CH}_{3}$ & $162.4, c i s-4-\mathrm{CH}_{3}$ & 162.4 \\
\hline & -41.1 & -7.5 & 3.5 & 1.1 & 0.9 & 5.3 & -4.1 & & & 0.7 & 0.7 \\
\hline \multirow[t]{2}{*}{ trans,trans-3,5-Dimethyl } & 123.7 & 147.2 & 165.5 & 145.7 & 157.6 & 160.1 & 157.6 & & trans-3- $-\mathrm{CH}_{3}$ & ${ }_{3} 169.1, c$ trans $-5-\mathrm{CH}_{3}$ & $168.5^{c}$ \\
\hline & -42.3 & -7.9 & 7.2 & 0.1 & -0.7 & 5.0 & -8.4 & & & $d$ & $d$ \\
\hline \multirow[t]{2}{*}{ cis,cis-3,5-Dimethyl } & 122.6 & 145.7 & 162.6 & 145.7 & 159.8 & 162.6 & 158.5 & & cis-3- $\mathrm{CH}_{3}$ & $168.5,{ }^{c} \mathrm{cis}-5-\mathrm{CH}_{3}$ & $169.1^{c}$ \\
\hline & -43.4 & -9.4 & 4.3 & 0.1 & 1.5 & 7.5 & -7.5 & & & $d$ & $d$ \\
\hline \multirow[t]{2}{*}{ 1-Methyl } & 120.3 & 150.1 & 170.5 & 163.3 & & & & 162.0 & & & \\
\hline & -37.3 & -4.9 & 4.9 & -0.3 & & & & -6.1 & & & \\
\hline \multirow[t]{2}{*}{ trans-1,2-Dimethyle } & 120.1 & 149.3 & 162.0 & $165.0^{c}$ & $164.2^{c}$ & 171.1 & 149.9 & 163.8 & trans $s^{e}-2-\mathrm{CH}_{8}$ & $I_{8} 175.9$ & \\
\hline & -31.1 & -1.9 & 5.3 & $f$ & $g$ & 5.3 & -6.8 & -6.1 & & 6.0 & \\
\hline \multirow[t]{2}{*}{ cis-1,3-Dimethyl } & 121.1 & 141.1 & 163.0 & 154.6 & 164.3 & 170.5 & 150.2 & 160.7 & $c i s^{e}-3-\mathrm{CH}_{3}$ & 168.1 & \\
\hline & -37.2 & -4.2 & 4.7 & -0.5 & -1.7 & 4.5 & -4.9 & -6.9 & & 0.5 & \\
\hline \multirow[t]{2}{*}{ trans-1,3-Dimethyle } & 120.7 & 141.1 & 165.4 & 154.0 & 163.6 & 170.5 & 149.8 & 163.0 & 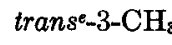 & $I_{8} 168.0$ & \\
\hline & -40.7 & -6.7 & 4.0 & -1.0 & 0.2 & 7.1 & -5.2 & -5.2 & & -0.2 & \\
\hline \multirow[t]{2}{*}{ trans-1,4-Dimethyle } & 120.6 & 152.0 & 162.7 & 157.4 & 154.4 & 171.4 & 150.1 & 161.6 & $\operatorname{trans} s^{6}-4-\mathrm{CH}$ & $I_{8} 169.3$ & \\
\hline & -36.7 & $h$ & $i$ & 0.1 & $j$ & 3.0 & $k$ & -6.6 & & 1.1 & \\
\hline \multirow[t]{2}{*}{ cis-1,4-Dimethyle } & 120.4 & 152.7 & 161.8 & 157.2 & 154.0 & 171.6 & 149.7 & 162.2 & $c i s^{e}-4-\mathrm{CH}_{3}$ & 169.5 & \\
\hline & -37.9 & -6.3 & 2.8 & -1.1 & -0.1 & 6.1 & -4.4 & -6.0 & & 1.3 & \\
\hline \multirow[t]{2}{*}{ 1,2,2-Trimethyl } & 117.9 & 152.8 & 155.5 & 171.2 & 166.6 & 172.0 & 153.6 & 167.3 & trans $s_{-2}-\mathrm{CH}$ & $\mathrm{I}_{3} 168.0,^{c} \mathrm{cis}^{\mathrm{e}}-2-\mathrm{CH}_{3}$ & 168. \\
\hline & -31.4 & -4.1 & 6.9 & 1.5 & $l$ & $m$ & -6.5 & -6.4 & & $n$ & $o$ \\
\hline \multirow[t]{2}{*}{ 1,3,3-Trimethyl } & 120.4 & 138.6 & 159.9 & 150.2 & 167.9 & 168.3 & 149.6 & 160.1 & $\operatorname{trans} s^{e}-3-\mathrm{CH}$ & $\mathrm{I}_{3} 162.3, \mathrm{cis}^{e}-3-\mathrm{CH}_{3}$ & 161.0 \\
\hline & -42.6 & -2.5 & -0.2 & 0.2 & -1.1 & 5.9 & -3.5 & -6.7 & & -0.7 & -0.1 \\
\hline \multirow[t]{2}{*}{ 1,4,4-Trimethyl } & 121.5 & 156.6 & 158.4 & 160.2 & 149.7 & 173.9 & 148.0 & 161.4 & trans $s^{e}-4-\mathrm{CH}$ & $\mathrm{I}_{3} 162.6, \mathrm{cis}^{e}-4-\mathrm{CH}_{3}$ & 162.6 \\
\hline & -34.1 & -3.9 & $p$ & 1.0 & -0.2 & 3.9 & $q$ & -7.0 & & 1.3 & 0.7 \\
\hline
\end{tabular}

a The upper numbers for each alcohol are the experimentally determined chemical shifts in parts per million upfield from carbon disulfide; the second values are substituent effects obtained by subtracting the chemical shifts in parts per million of cycloheptane or the corresponding methylcycloheptanes. ${ }^{b}$ From ref $11 \mathrm{a} .{ }^{\circ}$ Tentative assignments. ${ }^{d} 0.9$ or 1.5 ppm. ${ }^{\circ}$ Cis and trans refers to the 1-methyl group. $f-0.8$ or $-1.6 \mathrm{ppm} . \quad{ }^{g} 1.4$ or $2.2 \mathrm{ppm} .{ }^{h}-3.9$ or $-3.7 \mathrm{ppm} . \quad{ }^{i} 6.8$ or $7.0 \mathrm{ppm} . \quad j-1.3$ or $-1.5 \mathrm{ppm}$. $k-5.6$ or $-5.8 \mathrm{ppm} . \quad{ }^{l} 4.5$ or $3.8 \mathrm{ppm} . \quad{ }^{m} 9.2$ or $9.9 \mathrm{ppm} . \quad{ }^{n} 5.2$ or $5.4 \mathrm{ppm} . \quad{ }^{\circ} 0.6$ or $0.8 \mathrm{ppm} . \quad{ }^{p} 6.5$ or $5.9 \mathrm{ppm} . \quad{ }^{q}-4.5$ or $-3.9 \mathrm{ppm}$.

TABLE V

Pseudocontact Shifts of ${ }^{13}$ C Resonances in Some Cycloheptanols (In PPM)

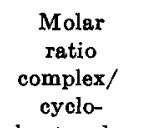

\begin{tabular}{|c|c|c|c|c|c|c|c|c|c|c|c|c|}
\hline \multirow[t]{2}{*}{ trans,trans-3,5-Dimethyl ${ }^{a}$} & 0.14 & -6.9 & -1.8 & -1.0 & -0.8 & -0.8 & -1.2 & -2.2 & & $3,5-\mathrm{CH}_{3}$ & -0.4 & -0.2 \\
\hline & 0.22 & -10.2 & -3.0 & -1.7 & -1.3 & -1.4 & -1.6 & -3.5 & & & 6 , & .4 \\
\hline \multirow[t]{2}{*}{ cis,cis-3,5-Dimethyl ${ }^{a}$} & 0.14 & -8.0 & -2.6 & -1.1 & -0.8 & -0.9 & -1.1 & -2.2 & & & -0.4 & -0.2 \\
\hline & 0.22 & -12.8 & -4.1 & -1.8 & -1.3 & -1.3 & -1.8 & -3.5 & & & -0.6 , & -0.4 \\
\hline 1,2,2-Trimeth & 0.24 & $b$ & -3.5 & -2.6 & -1.8 & $c$ & -2.8 & -5.4 & -6.8 & $2-\mathrm{CH}_{3}$ & $c$ & \\
\hline 1,3,3-Trimethyl ${ }^{d}$ & 0.15 & -6.2 & -1.6 & -0.6 & -0.6 & -0.5 & -0.8 & -1.6 & -2.1 & $\begin{array}{l}\operatorname{trans}^{\theta}-3-\mathrm{C} \\
\operatorname{cis}^{e}-3-\mathrm{CH}_{3}\end{array}$ & & $\begin{array}{l}-0.5 \\
-0.2\end{array}$ \\
\hline 1,4,4-Trimethyld & 0.10 & $b$ & -1.2 & -0.7 & -0.5 & -0.6 & -0.8 & -1.0 & -1.6 & $4-\mathrm{CH}_{3}$ & & -0.3 \\
\hline
\end{tabular}

${ }^{a}$ Shift reagent $\mathrm{Eu}(\mathrm{DPM})_{3} . \quad{ }^{b}$ Not observed. ${ }^{c}$ Obscured by the tert-butyl methyl carbon resonance of Eu(DPM $)_{3}$ at 164.5 ppm. ${ }^{d}$ Shift reagent $\mathrm{Eu}(\mathrm{fod})_{3} . \quad{ }^{\circ}$ Cis and trans refer to the 1-methyl group. 
the methyl carbons nonequivalent. Presumably, there is a relatively small effect of the equatorial hydroxyl on the environment of the methyls in 21, which is expected to be the most stable conformation for this substance.

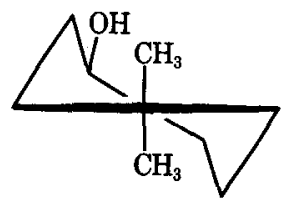

21

The two isomeric 3,5-dimethylcycloheptanols which have the methyl groups cis to each other show characteristic differences in the ${ }^{13} \mathrm{C} \mathrm{nmr}$ spectrum. The hydroxyl protons, however, have the same chemical shift and the same coupling constant as the carbinyl proton (Table III), indicating similar conformational positions for the hydroxyl groups. The pseudorotation itinerary of the twist-chair model, which contains 14 conformations, predicts a more equatorial hydroxyl group for the cis,cis isomer than for the trans,trans isomer. The substituent effects of the hydroxyl groups on the ${ }^{13} \mathrm{C}$ resonances reflect this trend. In one isomer, the $\alpha$ effect and the sum of the $\beta$ effects are more negative, while the sum of the $\gamma$ effects is less positive than for the other isomer, as would be expected for a higher equatorial character for the hydroxyl group of the former isomer which, therefore, should be the cis, cis structure.

The $\gamma$ interaction of the hydroxyl group in 1-methylcycloheptanol, as reflected by the chemical shifts, is somewhat larger than the $\gamma$ effect of a methyl group in 1,1-dimethylcycloheptane. This may indicate that 22

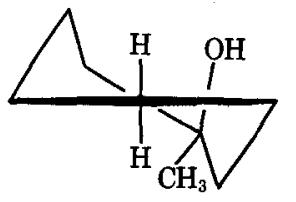

22

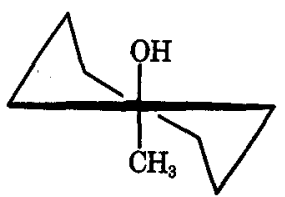

23 has some significant population relative to 23 . The principal product from 2-methylcycloheptanone and methyllithium appears to be the one with trans-methyl groups, because the chemical shift of the 1-methyl carbon is only $1.8 \mathrm{ppm}$ upfield from the corresponding peak in 1-methylcycloheptanol. If the addition were to give $c i s$-methyls, about a 6.5 -ppm upfield shift would be expected (compare cis- and trans-1,2-dimethylcycloheptane). The $\gamma$ effects of the hydroxyl in this compound are both $5.3 \mathrm{ppm}$, which appears to rule out 24 from being the only important conformation because it has only one strong $\gamma$ interaction. Significant population of 25 and 26 would balance the $\gamma$ effects of the hydroxyl, and these conformations are expected to be substantially more important than the corresponding ones for 1,1,2-trimethylcycloheptane because the relatively small hydroxyl group should not be so unfavorably situated in a $4 \mathrm{a}$ or $4 \mathrm{a}^{\prime}$ position of the twist-chair (1) as a methyl group.

The assignment of the two sets of lines of different intensities in the mixture of the 1,3-dimethylcycloheptanols to specific isomers has been made on the basis of the chemical shifts of the methyl carbons, the isomer with the low field 1-methyl being taken to have the methyl groups cis. With the exception of these and

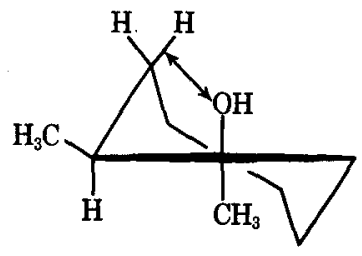

24

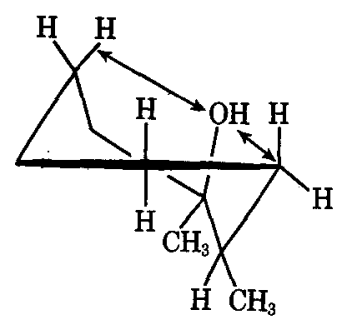

25

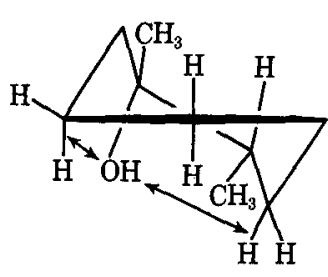

26 the resonances of $\mathrm{C}-3$, all the chemical shifts are rather similar.

Still more similar in their ${ }^{18} \mathrm{C}$ nmr spectra are the two 1,4-dimethylcycloheptanols. The assignments followed those for the 1,3-dimethyl compounds except that now cis and trans were exchanged. The number of favorable conformers with both the methyl groups in equatorial or isoclinal positions are five for the trans and four for the cis. The similarity in the chemical shifts of the two isomers is therefore not surprising. The asymmetry of the $\gamma$ interactions in these isomers can be explained by conformations 27 and 28 . The

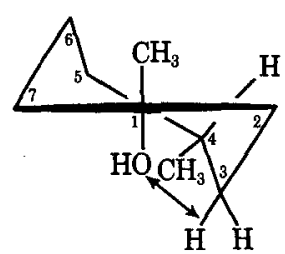

27

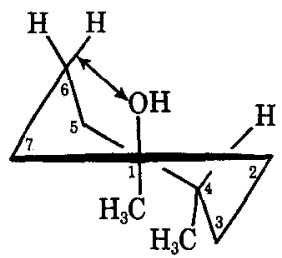

28
1,2,2-, 1,3,3-, and 1,4,4-trimethylcycloheptanols are rather highly substituted. Based on Hendrickson's conformational energies of the methyl group, and assuming half of these values for a hydroxyl group, one can calculate the energies of the possible conformations. The results suggest that, for all three cases, twist-chair forms should be more stable than other conformations by about $1 \mathrm{kcal} / \mathrm{mol}$. The most favorable conformer of 1,2,2-trimethylcycloheptanol should be 29 , which

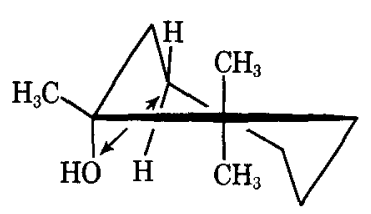

29

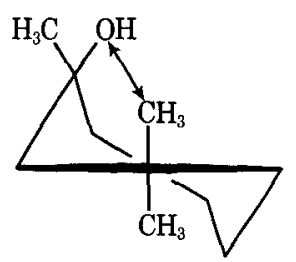

30 reflects the asymmetry of the $\gamma$ effect of the hydroxyl group on the resonances of C-6 and C-3. The small chemical-shift difference between the two 2-methyl carbons allows only an arbitrary assignment, while the peak for the 1-methyl carbon was positively identified by specific proton decoupling. 
TABLE VI

${ }^{13}$ C Chemical Shifts of Cycloheptanones Relative to Carbon Disulfide (in ppm)

\begin{tabular}{|c|c|c|c|c|c|c|c|c|c|c|c|}
\hline Registry no. & Cycloheptanane & C-1 & $\mathrm{C}-2$ & C-3 & C-4 & C-5 & $\mathrm{C}-6$ & C-7 & $2-\mathrm{CH}_{3}$ & $3-\mathrm{CH}_{3}$ & $4-\mathrm{CH}_{3}$ \\
\hline $502-42-1$ & Cycloheptanone ${ }^{a}$ & -18.9 & 150.1 & 169.3 & 163.1 & & & & & & \\
\hline $932-56-9$ & 2-Methyl & -19.9 & 147.2 & 159.9 & 164.5 & 163.3 & 168.8 & 150.9 & 176.1 & & \\
\hline $933-17-5$ & 3-Methyl & -17.7 & 141.7 & 162.0 & 153.9 & 164.5 & 168.9 & 149.4 & & 169.9 & \\
\hline $5452-36-8$ & 4-Methyl & -18.9 & 151.1 & 160.8 & 156.5 & 154.3 & 170.0 & 149.6 & & & 170.0 \\
\hline $7228-52-6$ & 2,2-Dimethyl & -21.7 & 146.1 & 154.0 & 168.2 & 162.5 & 166.7 & 153.5 & 167.6 & & \\
\hline $23438-70-2$ & 3,3-Dimethyl & -16.9 & 137.5 & 160.8 & 148.4 & $168.9^{b}$ & $168.1^{b}$ & 149.5 & & 163.9 & \\
\hline $35099-49-1$ & 4,4-Dimethyl & -18.6 & 154.1 & 156.9 & 159.9 & 149.8 & 173.3 & 149.8 & & & 164.6 \\
\hline 24291-91-6 & cis-3,5-Dimethyl & -18.0 & 141.2 & 162.2 & 144.6 & 157.0 & 160.4 & 150.4 & & 168.9 & 168.9 \\
\hline
\end{tabular}

TABLE VII

${ }^{13}$ C Chemical Shift Substituent Effects (in PpM) on Cycloheptane, Methylcycloheptane, and 1,1-Dimethylcycloheptane Produced by a Ketone Group

\begin{tabular}{lccccc}
\multicolumn{1}{c}{ Cycloheptanone } & $\alpha$ Effect & $\beta$ Effect & $\gamma$ Effect & $\delta$ Effect & Effect on the Methyl Ca $^{a}$ \\
Cycloheptanone & -183.2 & -14.3 & 5.0 & -1.2 & $8.0(\gamma)$ \\
2-Methyl & -174.9 & $-10.4,-14.7$ & $4.9,5.2$ & $-1.1,-0.3$ & $1.8(\delta)$ \\
3-Methyl & -183.3 & $-13.3,-14.2$ & $4.4,5.3$ & $-1.1,-1.1$ & $1.9(\epsilon)$ \\
4-Methyl & -182.5 & $-14.5,-14.0$ & $5.8,4.4$ & $-1.1,-0.7$ & $5.9(\gamma)$ \\
2,2-Dimethyl & -171.6 & $-13.1,-15.2$ & $4.1,5.0$ & $-0.5,0.8$ & $2.2(\delta)$ \\
3,3-Dimethyl & -185.6 & $-12.4,-12.2$ & $1.6,6.4$, or 5.7 & $-1.5,0.2$, or -0.5 & $2.9(\epsilon)$ \\
4,4-Dimethyl & -180.3 & $-14.6,-11.9$ & $7.0,4.6$ & $\mathbf{0 . 7},-0.1$ & $1.3(\delta), 1.3(\epsilon)$ \\
cis-3,5-Dimethyl & -184.0 & $-13.9,-15.6$ & $3.9,5.3$ & $-1.0,-1.3$ &
\end{tabular}

a. Type of interaction in parentheses.

The most stable conformation of 1,3,3-trimethylcycloheptanol should be 30 . The data in Table IV show that the C-3 shift is not influenced by the hydroxyl group. However, C-3 has no attached hydrogens and is likely to be less susceptible to a $\gamma$ effect, as judged from other examples. ${ }^{14}$ The hydroxyl group does interact with the 1-methyl group which is on the same side of the ring, and this one is therefore assigned the upfield resonance. Compared to other 1-methylcycloheptanols, the $\alpha$-substituent effect of the hydroxyl group is quite high $(-42.6 \mathrm{ppm})$. Apparently, as C-1 loses its directly attached hydrogen on introduction of the hydroxyl group, there is at least partial loss of the positive $\gamma$ shift exerted by the 3 -methyl groups. The result is a 8.5-ppm more negative shift than is found for the corresponding carbon of 1,4,4-trimethylcycloheptanol.

C. Methylcycloheptanones. - Studies of the conformational problems of cycloheptanones have been carried out with halogen ${ }^{28}$ and alkyl derivatives. ${ }^{29,30}$ It has been concluded from ir spectra that for cis-2,7dichlorocycloheptanone the conformer with two equatorial chlorines is more stable by $1.1 \mathrm{kcal} / \mathrm{mol}$ than the diaxial one. ${ }^{28}$ Allinger has reported the enthalpy difference between cis- and trans-3,5-dimethylcycloheptanone to be $0.8 \mathrm{kcal} / \mathrm{mol}$, the cis isomer being the more stable. ${ }^{29}$ Evidence for the twist-chair conformation of alkylcycloheptanones has been derived from benzeneinduced shifts on the proton spectra. ${ }^{30}$

The chemical shifts obtained from the ${ }^{13} \mathrm{C} \mathrm{nmr}$ spectra of some methylcycloheptanones in dioxane are given in Table VI. (See also Table VII.) The resonances of $\mathrm{C}-2$ and $\mathrm{C}-7$ have been identified by selective decoupling of the attached protons. Further assignments have been obtained unambiguously by compari-

(28) R. Borsdorf, W. Flamme, H. Kumpfert, and M. Mühlstädt, Tetrahedron, 24, 65 (1968), and references cited therein.

(29) N. L. Allinger, J. A mer. Chem. Soc., 81, 232 (1959).

(30) A. Zschunke, F.-J. Strüber, and R. Borsdorf, J. Prakt. Chem., s11, 296 (1969) son of the spectra of 3-methylcycloheptanone-2,2,6,6-d4 and 4-methylcycloheptanone-3,3,7,7-d $d_{4}$ with those of the corresponding nondeuterated ketones. Earlier ${ }^{31}$ we did not properly characterize the resonances of C-3 and C-4 of the unsubstituted cycloheptanones. This has now been achieved with Eu(DPM) $)_{3}$ in benzene solutions (in which the chemical shifts differ from those in dioxane by less than $1 \mathrm{ppm}$, in the absence of the paramagnetic chelate). At a molar ratio of ketone/complex of 3.0, the four different carbons moved downfield by $10.8,3.4,2.4$, and $1.2 \mathrm{ppm}$, and we have assumed that the 1.2-ppm shift is that of C-4. For the 2-, 3-, and 4-methylcycloheptanones, the methine carbon resonances are easy to identify, and we have used these as references for the carbonyl substituent effects. ${ }^{31}$ It is evident that the $\gamma$-shift effect of a carbonyl group in a cycloheptanone is much more positive than for cyclohexanones. ${ }^{31}$ The small $\gamma$ effects of carbonyl groups on cyclohexane resonances has been interpreted as evidence for flattening of the six-membered ring by the $\mathrm{sp}^{2}$ hybridized carbonyl carbon. ${ }^{31}$ The large $\gamma$ carbonyl effects in cycloheptanones suggest that a $\mathrm{sp}^{2}$ center does not critically affect the geometry of the cycloheptane ring. This could be a consequence of the relatively large bond angles in cycloheptane, which are, on the average, about $3^{\circ}$ larger than in cyclohexane, according to the predictions of Hendrickson ${ }^{4 c}$ and the experiments of Groth. ${ }^{9}$ It is noteworthy that the carbonyl carbon resonances are relatively invariant as respects methyl substitution on the ring. This was also observed for alkylcyclohexanones. ${ }^{31}$

\section{Experimental Section}

2-Methyl-, ${ }^{32}$ 3-methyl-, ${ }^{20,33}$ 4-methyl-, ${ }^{33}$ 2,2-dimethyl-, ${ }^{32} 3,3$ dimethyl-, ${ }^{34}$ 4,4-dimethyl-, ${ }^{6 c}$ and cis-3,5-dimethylcyclohepta-

(31) F. J. Weigert and J. D. Roberts, J. Amer. Chem. Soc., 92, 1347 (1970). (32) M. Godchot and G. Cauquil, C. R. Acad. Sci., 188, 795 (1929).

(33) C. Djerassi, B. F. Burrows, C. G. Overberger, T. Takekoshi, C. D. Dutsche, and C. T. Chang, J. Amer. Chem. Soc., 85, 949 (1963).

(34) M. Mousseron and G. Manon, Bull. Soc. Chim. Fr., 392 (1949). 
TABLE VIII

Yields, Boiling Points, and 'H Chemical Shiftsa (In ppm Downfield from Tetramethylsilane) of Some Cycloheptanols

\begin{tabular}{|c|c|c|c|c|c|c|}
\hline Substituents & Yield, \% & $\mathrm{Bp},{ }^{\circ} \mathrm{C}$ (Torr) & 1-H & $2 \mathrm{H}-7 \mathrm{H}$ & $1-\mathrm{CH}_{8}$ & $2-, 3-, 4-, 5-\mathrm{CH}_{8}$ \\
\hline $\left.\begin{array}{l}\text { cis-cis-3,5-Dimethyl } \\
\text { trans-trans-3,5-Dimethyl }\end{array}\right\}$ & 80 & $84-86(8)$ & 3.88 & $1.1-2.0$ & & $\sim 0.9$ \\
\hline 2,2-Dimethyl & 80 & $92-94(12)$ & 3.41 & $1.0-2.1$ & & $0.89,0.97$ \\
\hline 3,3-Dimethyl & 75 & $92-94(9)$ & 3.75 & $1.2-1.9$ & & $0.91,0.97$ \\
\hline 4,4-Dimethyl & 79 & $97-99(9)$ & 3.76 & $1.1-2.1$ & & $0.88,0.91$ \\
\hline trans-1,2-Dimethyl & 81 & $83-86(8)$ & & $1.1-2.0$ & & 0.97 \\
\hline $\left.\begin{array}{l}\text { cis-1,3-Dimethyl } \\
\text { trans-1,3-Dimethyl }^{b}\end{array}\right\}$ & 80 & $70-74(4)$ & & $1.1-2.0$ & $\left\{\begin{array}{l}1.23 \\
1.26\end{array}\right\}$ & 0.95 \\
\hline $\left.\begin{array}{l}\text { trans-1,4-Dimethylc } \\
\text { cis-1,4-Dimethyl }\end{array}\right\}$ & 88 & $79-82(6)$ & & $1.1-2.0$ & 1.21 & 0.90 \\
\hline 1,2,2-Trimethyl & 93 & $86-90(6)$ & & $1.1-2.1$ & 1.15 & $0.90,0.95$ \\
\hline 1,3,3-Trimethyl & 86 & $83-87(8)$ & & $1.3-1.9$ & 1.22 & $0.92,1.02$ \\
\hline 1,4,4-Trimethyl & 85 & $89-91(10)$ & & $1.0-1.9$ & 1.22 & $0.89,0.91$ \\
\hline
\end{tabular}

a Taken in $\mathrm{CDCl}_{3}$ as solvent. ${ }^{b}$ Cis: trans ratio, 60:40. ' Trans: cis ratio, 55:45.

none ${ }^{16}$ were prepared as described in the literature. 2-Methylcycloheptanone- $2,7,7-d_{3}$ and 3-methyl- and 4-methylcycloheptanone- $2, Q, \gamma, \gamma_{-} d_{4}$ were obtained from the nondeuterated ketones by means of sodium carbonate and deuterium oxide as described for other cyclic ketones. ${ }^{35}$ 3-Methylcyclohexanone$2,2,6,6-d_{4}$, obtained by exchange ${ }^{35}$ with diazomethane, ${ }^{33}$ gave a mixture of 3-methylcycloheptanone- $2,2,6,6-d_{4}$ and 4-methyl cycloheptanone-3,3,7,7-d, which was separated on our efficient spinning-band column.

Reduction of 2-methylcycloheptanone with $\mathrm{H}_{2} / \mathrm{Pt}$ or $\mathrm{Na} / \mathrm{C}_{2}-$ $\mathrm{H}_{5} \mathrm{OH}$ resulted in mixtures of the 2-methylcycloheptanols in which one or the other of the two isomers was in excess. ${ }^{19,36}$ The 3-methylcycloheptanols were obtained as 1:1 mixture of cis-trans isomers by $\mathrm{LiAlH}_{4}$ reduction of the corresponding ketone. ${ }^{19}$ Chromatography of $1 \mathrm{~g}$ of this mixture on $50 \mathrm{~g}$ of neutral $\mathrm{Al}_{2} \mathrm{O}_{3}$ (Woelm, activity III) was assayed with pentane and pentane-ether as solvents. The first eight $100-\mathrm{ml}$ portions eluted with pentane contained no alcohol. With pentane-ether, the ninth fraction contained $130 \mathrm{mg}$ of the practically pure trans isomer, while in fractions 12 and $13(200 \mathrm{mg})$ the cis-trans ratio was $2: 1$. Reduction of 4-methylcycloheptanone with lithium aluminum hydride resulted in a 1:1 mixture of cis-trans isomers. However, hydrogenation, as described for 2-methylcycloheptanone, ${ }^{18,36}$ produced a mixture in which the cis compound was the more abundant component (about 60\%). Reduction of cis-3,5-dimethylcycloheptanone with lithium aluminum hydride also gave a 1:1 mixture of two isomers which, by chromatography on neutral $\mathrm{Al}_{2} \mathrm{O}_{3}$ as above, led to enrichment of the cis,cis isomer to about $60 \%$ in the last fraction. A mixture of about the same ratio was obtained by reduction of the ketone with $\mathrm{H}_{2} / \mathrm{Pt}$. The deuterated cycloheptanones were all reduced by lithium aluminum hydride and the ${ }^{13} \mathrm{C} n m r$ spectra were examined without further attempts at separation. The 2,23,3- and 4,4-dimethylcycloheptanols were obtained by lithium aluminum hydride reduction of the corresponding ketones. Table VIII summarizes the properties of some secondary and tertiary cycloheptanols prepared in this work. The latter alcohols were obtained in addition of $30 \mathrm{mmol}$ of methyllithium (about $15 \mathrm{cc}$ of a commercial $2.1 \mathrm{M}$ solution in ether) to $15 \mathrm{mmol}$ of the appropriate cycloheptanone, dissolved in $10 \mathrm{cc}$ of anhydrous ether. The mixture was heated gently under reflux for $15 \mathrm{hr}$, then hydrolyzed by addition of water. The ether phase was separated, dried over anhydrous sodium sulfate, and distilled. The products were found to be free of major impurities from their proton and ${ }^{13} \mathrm{C} \mathrm{nmr}$ spectra. The isomer ratios of the cycloheptanol mixtures were estimated either from the hydroxyl proton intensities in the spectra in dimethyl sulfoxide or from the ${ }^{13} \mathrm{C}$ nmr spectra.

1-Methylcycloheptanol, $\operatorname{Eu}(\mathrm{DPM})_{3}, \operatorname{Eu}\left(\mathrm{fod}_{3}\right)_{3}$, and methylcycloheptane were commercial materials used without further

(35) E. Premuzic and L. W. Reeves, Can. J. Chem., 40, 1870 (1962).

(36) M. Godchot and G. Cauquil, C. R. Acad. Sci, 190, 642 (1930). purification. The samples of the dimethyl- and 1,1,3-trimethylcycloheptanes were provided by Professor J. B. Hendrickson.

1,1,4-Trimethylcycloheptane.-1,4,4-Trimethylcycloheptanol $(2.9 \mathrm{~g})$ and $1 \mathrm{~g}$ of iodine were mixed and heated to $80-100^{\circ}$ under a pressure of about 1 Torr. The volatile products were collected at $-75^{\circ}$, taken up in ether, washed with aqueous sodium bisulfite solution to remove some iodine, dried over sodium sulfate, and distilled. After removal of the ether, a fraction of $900 \mathrm{mg}$ was obtained, bp $71-75^{\circ}$ (30 Torr). The vpc on Carbowax $20 \mathrm{M}$ showed two peaks of equal intensity. The distillate in $10 \mathrm{ml}$ of acetic acid took up $275 \mathrm{ml}$ of hydrogen in the presence of $150 \mathrm{mg}$ of $\mathrm{PtO}_{2}$ over $2 \mathrm{hr}$. The catalyst was removed by filtration, the filtrate was neutralized with potassium hydroxide solution and extracted with ether, and the extract was dried over sodium sulfate. Distillation gave a fraction of bp $72-75^{\circ}$ (30 Torr), amounting to $700 \mathrm{mg} \mathrm{(27 \% )} \mathrm{which,} \mathrm{in} \mathrm{the} \mathrm{vpc} \mathrm{(Carbowax} \mathrm{20M),}$ showed only one peak. The proton spectrum (neat + TMS) showed $2 \mathrm{H}-7 \mathrm{H}$ at $\delta 0.98-2.03$ and $\mathrm{CH}_{3}$ at $\delta 0.88$. The same procedure, starting with 1,2,2-trimethylcycloheptanol, gave a $39 \%$ yield of a mixture of $\mathrm{C}_{10} \mathrm{H}_{20}$ hydrocarbons which, by vpc on two different columns (UCC/W98, silicon oil SE-30), showed two major products, each abundant to the extent of about $44 \%$. The carbon-13 spectrum showed one of these substances to be tert-butylcyclohexane.11a The other product was assumed to be 1,1,2-trimethylcycloheptane (see text).

$\mathrm{Nmr}$ Spectra.-The ${ }^{18} \mathrm{C}$ spectra of the cycloheptanols and cycloheptanones were taken on dioxane solutions. The measurements of the pseudocontact shifts, however, were made on benzene solutions. The cycloheptanes were run in carbon disulfide with $20-30 \%(\mathrm{v} / \mathrm{v})$ of tetramethylsilane, as required. The resonances of the carbons of the solvents were used as internal references. The chemical shifts reported here have all been corrected to carbon disulfide as external reference by the relationship $\delta_{\mathrm{C}}=\delta_{\mathrm{C}} \mathrm{C}^{\text {dioxane }}+126.2 \mathrm{ppm}, \delta_{\mathrm{C}}=\delta_{\mathrm{C}}^{\text {benzene }}+64.55$ ppm, and $\delta_{\mathrm{C}}=\delta_{\mathrm{C}}$ tetramethylsilane $+192.5 \mathrm{ppm}$, and were reproducible to $\pm 0.1 \mathrm{ppm}$. Most of the spectra were taken with a digital frequency sweep spectrometer, operating at $15.08 \mathrm{MHz}$, with its associated proton decoupler equipped with a narrow-band pseudorandom noise generator.11a The proton signals of the solvents provided a proton-field frequency lock. Some of the spectra were obtained with a Varian HR-220 spectrometer, operating at $55.34 \mathrm{MHz}$, and equipped with a proton decoupler and a pseudorandom noise generator. This instrument was used in the continuous-wave or the Fourier-transform mode. For the latter purpose, a Varian $620 \mathrm{i}$ computer was interfaced with the spectrometer.

Acknowledgment.-We are deeply indebted to Professor James B. Hendrickson of Brandeis University for the loan of samples of the dimethyl- and 1,1,3trimethylcycloheptanes studied in this research. 